\title{
A Comparative Analytical Study between Some of the Mechanical Laws to Extract the Explosive Power of the Legs to the Students of the Faculty of Physical Education
}

\author{
Nihad A. Qadir*, Nawzad H. Darweesh \\ School of the Physical Education, Koya University Daniel Mitterrand Boulevard, Koya, Kurdistan Region, Iraq
}

\begin{abstract}
The resultant measure of various tests are main theme which the researcher is going to shed light on, that also includes the explosive power measurement of the legs especially the selective test of (Sargent), that depends on the distance that jumps out laboratory vertically, and that was accredited test for a decade. that's why all sporty activities need an explosive power of the legs and their measurements are a necessary for the sporty training, the purpose of the above mentioned test is to valuate the level of the explosive power of the legs muscle during bouncing (jumping) in vertical shape, the vertical jump is defined as the highest point that the athlete can touch from a standing jump, less the height that the athlete can touch from a standing position and thus a jump is a rose by centimetre that's indirect measurement for the explosive power of the legs muscle in the sport researches or previous equation sport. Therefore, by reaching a persuasive scientific result we do achieve service for the company which designate sporty equipment's for the sake of getting an accurate law to measure the explosive power of the legs. Through this research the researcher is trying to study and shed light on all biomechanical existing laws which was used by other researchers in the previous and compare with some of them that means by the comparison of these laws the problem would be summed up so as to get any law that serve this mechanical test, and which one of them is more accurate than any others scientifically, therefore through our knowledge about mechanical law we serve more accurate to the scientific side.
\end{abstract}

Keywords General power, Harman, Johnson laws, Sargent

\section{Introduction}

This scientific research is a systematic means to discover the scientific logical change of the phenomena trends and problems, therefore it has hypotheses and guesses which is a sign for temporary solutions that can be emphasized on by following realizable reasons and goals, which can be measured by nature and social laws to govern the people, and aims to fulfill the results and researcher's wish or the sides that he wants to search for a selective purpose.

In more sporting activity or it's better to say in all sporting activity a force is needed which is an immense base to move, also it needs a capacity whether it is explosive or as fast as distinctive skill, as well as the difference between strength and capacity physiologically is considered as a difficult work, surely there are difference between them and that is the essence of training which trainers depend on it for the purpose of advancing of these two qualities'as well as for studying the basic mechanical properties and mechanisms of

* Corresponding author:

nihad.ayub@koyauniversity.org (Nihad A. Qadir)

Published online at http://journal.sapub.org/sports

Copyright (c) 2017 Scientific \& Academic Publishing. All Rights Reserved the neuro-muscular system associated with production of maximum movement performance [1] Explosive power means using resulting force as the production of the central muscle contraction maximum: in a specific moment of time that extends the joints and effect on it, This concept is a simplification of a take off phase as the dominant muscle groups for the ankle, knee and hip joints engage at different time points during the take off [2], Such as that occurs in the joints of the body as well as in moments of raising, jumping skills or beating ... etc. And this force can be made for a long time, and it shall be a fast force in a moment of time, and the explosive ability varies from one player to another because (1921) [3] So much use in the field of physical education whether it was used in measuring the explosive power (ability) to leg muscles in a private fitness research or for athletes. the mathematical laws are considered as the basic key through which we can reach the accurate skills and addressing the athletes the gaps that they face and directing them to the better order, because what we call law is nothing only to solve the numbers that were get from the laboratory, when we want to measure what effort law or skill.

"All different athletes couldn't be dealt with the basis of time that was done to them without taking into the mass account of each athlete [4], that depend on used tests to 
measure the strength without depending mechanically for the sake of getting the mathematical formula. So through this research the researcher tries to study all biomechanical and existing laws that was used by former researcher and compared them with each other it means comparing these laws for the sake of reaching the accurate law that serve this test mechanically and which one of them is more accurate than the other scientifically, therefore through our knowledge of the accurate mechanical law we can serve scientific aspects as well as sooner reality of the ability of legs to the laboratory in the mentioned test results.

And that the research problem lies through research and investigation we reach out there that scientific several in the sports field that you need to study and address them and try to develop scientific solutions to them and employ the results of these studies to serve the sporting achievement and scientific research, and one of the problems seen by the researcher is the problem of measuring the results of testing problems different including the explosive power of the legs measure, especially the identification test (Sargent) that depend on the distance that jumps out laboratory vertically and is approved in a decade the test, so the researcher is trying to address this test in accordance with the mechanical basics without relying only on the distance through several mechanical laws they applied earlier investigators in the field Biomechanic.

So researcher tries through this research study all the laws Biomechanic the existing used by former researchers and compared to each other any are summarized the problem in a comparison of these laws in order to reach any law served the test of the mechanic and whichever is more accurate from scientific point so through our knowledge of mechanical law more accurate service has accomplished a scientific sideand also close to the reality of the ability of the legs to the laboratory in the said test result.

\subsection{Research Goals}

1. Identify the explosive power of the legs values of different mechanical laws for the students of the Faculty of Physical Education.

2. Identify the differences between some of the mechanical laws to extract the explosive power of the legs for the students of the Faculty of Physical.

\subsection{Imposing Search}

There are significant differences between some of the mechanical laws to extract the explosive power of the legs of the students of the Faculty of Physical Education.

\section{Material and Methods}

\subsection{Participants}

Was the research sample of students of School of Physical Education for the school year (2015-2016) if the researcher tests the sample purposively amounted to (20) students who find vertical jump test of fortitude and who are playing in the university team of different Games. If the average-weight (70.77 kg) and height $(178 \mathrm{~cm})$ and age (23 years) shows the Table (1) Specifications of the research sample.

Table (1)

\begin{tabular}{|c|c|c|c|c|c|c|}
\hline Sequence & Variables & Maen & S.D & Mode & Median & Skews \\
\hline $\mathbf{1}$ & Weight & 70.77 & 9.44 & 55.20 & 69.55 & 0.389 \\
\hline $\mathbf{2}$ & Height & 178 & 5.00 & 175.00 & 178.00 & $0.646-$ \\
\hline $\mathbf{3}$ & Age & 23 & 1.49 & 23.00 & 23.00 & 0.469 \\
\hline
\end{tabular}

\subsection{Devices Used in the Search}

1. Type a video camera (Casio-High Speed-Exilim) made (Japanese) number (1) speed (1000-420-210) frem / sec.

2. Weight measurement device.

3. Tests and measurements used in the search.

\section{SARGENT VERTICAL JUMP TEST [5]}

Measuring the difference between a person's standing reach and the height to which he/she can jump and touch has been widely (although possibly erroneously) used as an index of power. If body weight and the speed in performing the jump are not part of the measurement, one cannot regard this test as a true measure of power. (Certainly a $70 \mathrm{~kg}$ subject who jumps 1 meter vertically produces less power than a

All tests will be performed in the following manner:

1. Determine standing reach height

2. Subject will perform three trials; record the best height

3. Calculate the power output as follows:

a. Find difference between best vertical jump height and standing reach height.

b. Calculate power in $\mathrm{kgm} / \mathrm{sec}$ using.

\subsection{Laws Used (Variables Research)}

1- General Power $(\mathrm{W})=$ work $/$ Time $=$ force $\mathrm{x}$ distance/ Time $=$ mass $\mathrm{x}$ VJ $(\mathrm{cm}) \times$ 9.81/ Time [6]

2- (Harman) Peak power $(\mathrm{W})=61.9 \mathrm{x}$ VJ $(\mathrm{cm})+36.0 \mathrm{x}$ mass $(\mathrm{kg})+1822$ [7].

3- (Johnson) Peak power $(\mathrm{W})=78.5 \mathrm{x}$ VJ $(\mathrm{cm})+60.6 \mathrm{x}$ mass (kg) -15.3 x height (cm) -1308 [8].

4- (Sayers) Peak power $(\mathrm{W})=60.7 \mathrm{x}$ VJ $(\mathrm{cm})+45.3 \mathrm{x}$ mass (kg) - 2055 [9].

\subsection{The Main Experiment}

The main researcher held a brief summary The experiment two days (3-4 / 1/2015) in the Hall (Faculty of Physical Education) and closed at ((10 Am and the presence of support staff and all members of the research sample were as follows:

First day: physical measurements.

Second day: test the explosive power of the legs.

And after the test and measurement application is the end 
of the study, the researcher unloaded own physical measurements registration forms and test the explosive power of the legs in a special for the detection and analysis of a photographer testing process as a prelude to submission of data for statistical processing.

\subsection{Statistical Methods}

The researcher after emptying data and submitting it for statistical processing by the computer which has been used electronic system (SPSS) for statistical analysis of research data.

\section{Results}

After that, the researcher eradication raw data from research laws introduced by the four tables in descriptive statistics and then addressed the results by using analysis of variance (Anova) and the law less significant difference (Tukey HSD), as follows:

Table (2). Between the Arithmetic mean, standard deviations, and the highest and lowest degree

\begin{tabular}{|c|c|c|c|c|c|}
\hline Data & Measruing Unit & Maen & S.D & Minimum & Maximum \\
\hline General Power & \multirow{4}{*}{ kg.m/sec } & 302.9681 & 78.58410 & 151.82 & 445.92 \\
\hline Harman & & 4376.5721 & 328.63738 & 3824.28 & 5116.57 \\
\hline Johnson & & 385.5500 & 870.15041 & -471.00 & 3403.00 \\
\hline Sayers & & 1153.1500 & 413.33525 & 458.00 & 2086.00 \\
\hline
\end{tabular}

Table (3). Indicates analysis of variance (F) and the value of probabilistic variables Search

\begin{tabular}{|c|c|c|c|c|c|}
\hline & Sum of Squares & Df & Mean Square & F & \multirow{2}{*}{ Sig (p.Value) } \\
\cline { 1 - 4 } Between Groups & $2.129 \mathrm{E} 8$ & 3 & $7.095 \mathrm{E} 7$ & \multirow{2}{*}{282.942} & \multirow{2}{*}{$\mathbf{0 . 0 0 0}$} \\
\cline { 1 - 4 } Within Groups & $1.980 \mathrm{E} 7$ & 76 & 260546.437 & & \\
\hline Total & $2.410 \mathrm{E} 8$ & 79 & & \\
\hline
\end{tabular}

*. The mean difference is significant at the 0.05 level.

Table (4). Shows the significant differences between research variables (the four laws) using the least significant difference value, (Tukey HSD)

\begin{tabular}{|c|c|c|c|c|c|c|c|c|}
\hline \multirow{2}{*}{ Data } & \multicolumn{2}{|c|}{ General Power } & \multicolumn{2}{c|}{ Harman } & \multicolumn{2}{c|}{ Johnson } & \multicolumn{2}{c|}{ Sayers } \\
\cline { 2 - 9 } & $\begin{array}{c}\text { Mean } \\
\text { Difference } \\
\text { (I-J }\end{array}$ & Sig & $\begin{array}{c}\text { Mean } \\
\text { Difference } \\
\text { (I-J }\end{array}$ & Sig & $\begin{array}{c}\text { Mean } \\
\text { Difference } \\
\text { (I-J }\end{array}$ & Sig & $\begin{array}{c}\text { Mean } \\
\text { Difference } \\
\text { (I-J }\end{array}$ & Sig \\
\hline General Power & \multicolumn{2}{|c|}{} & $*$ & $*$ & & & $*$ & $*$ \\
\hline harman & $4073.603 *$ & 0.000 & & & $*$ & $*$ & $*$ & $*$ \\
\hline Johnson & 82.581 & 0.956 & -3.802 & 0.000 & & & $*$ & $*$ \\
\hline sayers & $850.181 *$ & 0.000 & -3.223 & 0.000 & $578.700 *$ & 0.000 & & \\
\hline
\end{tabular}

*. The mean difference is significant at the 0.05 level.

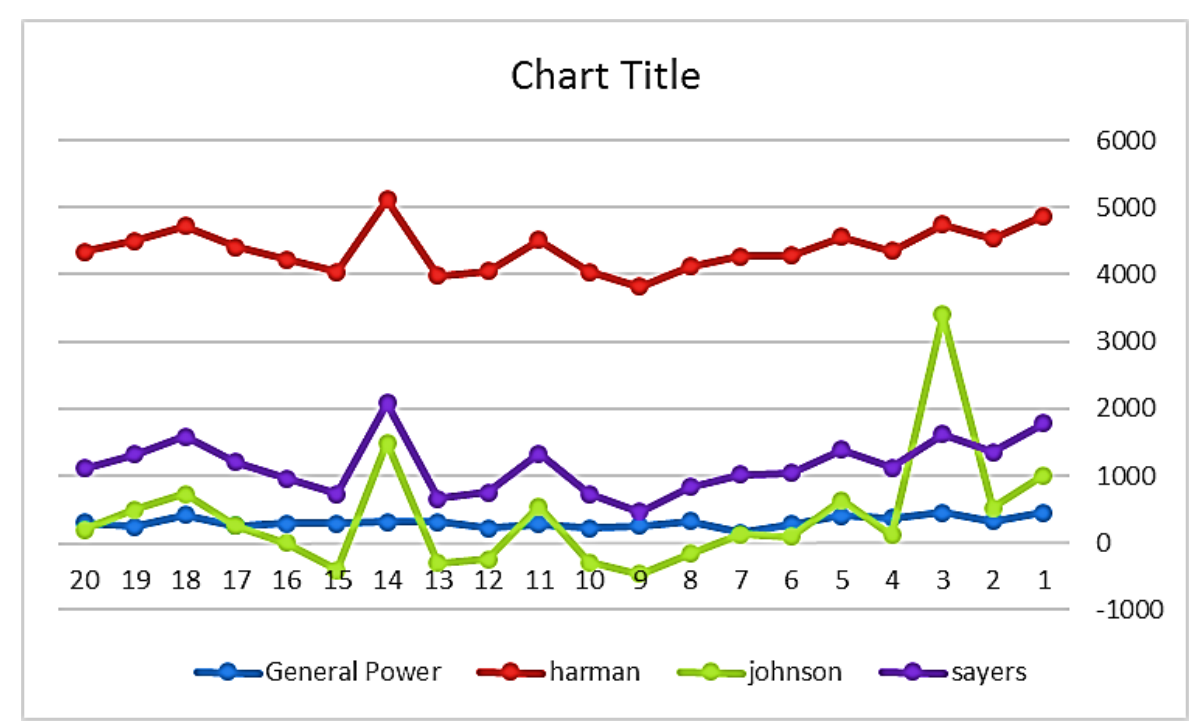

Figure 1. Represents the results of the vertical jump by four equations 


\section{Discussion}

Through out what was achieved by statistical treatments of sample (four equations) as well as descriptive statistics of the performance of vertical jump which is also includes and four different mechanical equations will be analysed, also various analysis and differences in analysis morally that makes researcher refer to the view of the problem in his researcher through the outcome of the mechanical equations to measure the explosive capacity of the legs. For it and through analysis of variance table (3) which shows the entire differences between the four equations through value $(\mathrm{F})$ calculated (282.942) and the probability value $(0.000)$ which is less than (5\%) necessitated the researcher an action statistics valued at (Turkey HSD) while there was a significant difference between all equations and the probability value (0.000) which is less than (5\%) as it was shown in table (4) except for lacking of immense difference between the equation (General power) and equation (Johnson ) value of (82.581) and probability (0.956) it was greater than (5\%) attribute the researchers reason for that to be the end of the equation (Johnson) he negates this figure (1308) depending on this division (peak power $(\mathrm{W})=78.5 \mathrm{x} \mathrm{VJ}(\mathrm{cm})+60.6 \mathrm{x}$ mass (kg) -15.3x height (cm) - 1308) through this division the results will be negative because of the individual differences between players and because the equation (general power) which the time is taking a great role here because when you divide the time immediately at least the value of the capacity depending (power $=$ mass $*$ acceleration *distance / time) [10] fig when the power player (784) depending on the force law (Newton 's Second Law) $(\mathrm{F}=\mathrm{ma})$ [11], capacity equal to $(448)$ when jumping distance $(0.48 \mathrm{~cm})$ and a time (0.84) by this the researcher will get the result that was imposed by the difference between the capacity to extract the laws and when you return to (Tukey HSD) table to see significant differences that was in favor of any questions we see that the difference was in favor of a modified third (Harman) as shown in the figure above, So it is necessary to know any equation serve the sports performance and at all sports specialist to be familiar with them as well as the manufacturers of sports equipment This suggests that trainers must consider in assessing the athlete reaction capabilities of their own through more than just one way to jump [12].

\section{Conclusions}

After viewing the results, the researcher to the following conclusions:

1. There are no significant differences between both (General Power) and (Johnson) Law.
2. When in Once are no significant differences (Tukey HSD) is used, the differences will be in favor of law (Harman).

3. There is a difference in the results between the rest of the laws between them.

4. Jump factor that [has a direct relationship, as during the taken time in (General Power) law power output is changing dramatically comparison with the rest of the laws.

5. Emphasize not only to jump only as a guide to the explosive ability of the individual during the application of scientific research distance.

\section{REFERENCES}

[1] B. MF, Effect of unloading and loading on power in simulated countermovement and squat umps. Med Sci Sports Exerc, 2014; 46: 1176-84.

[2] V. J. D. C. D. Lees A, Understanding how an arm swing enhances performance in the vertical jump. J Biomech, 2004a; 37: 1929-1940.

[3] Asama. A. Taai, “Iraqi Sport's Academy,” January 2009. [Online]. Available: http://www.iraqacad.org/Lib/usama/usa ma2.htm.

[4] M. Muhamad. A. Shahata, Physical measurements and tests of motor performance guide, askandarea, 2000, p.90.

[5] Untitled, "Evaluation of the immediate energy system," [Online]. Available: http://web.cortland.edu/buckenmeyerp/f all2004/labimmediate.html.

[6] S. E. G. ,. P. 1. -. 2. (Brian J. Sharkey, "powered by weebly -Power - Jump Mat test,” 296 2014. [Online]. Available: http://kwoodhambtg.weebly.com/.

[7] E. e. a. Harman, "Estimation of Human Power Output From Vertical Jump,” Journal of Applied Sport Science Research, vol. 5, no. 3, pp. 116-120, 1991.

[8] D. L. a. B. R. Johson, "Power Output Estimate in University Athletes," Journal of strength and Conditioning Research, vol. 10, no. 3, pp. 161-166, 1996.

[9] S. e. a. SAYERS, Cross-validation of three jump power equations, Med Sci Sports Exerc, 1999, Apr. 31, p. 572.

[10] Untitled, “physics forums,” 27 Jan 2010. [Online]. Available: https://www.physicsforums.com/threads/calculating-distance -and-time-given-mass-velocity-and-force.373254/.

[11] I. Newton, “wikipedia,” 12 April 2017. [Online]. Available: https://en.wikipedia.org/wiki/Newton\%27s_laws_of_motion.

[12] R. H. .. al, "Assessing Reactive Strength Measures in Jumping and Hopping Using the Optojump TM System," Journal of Human Kinetics, vol. 54, no. 4, p. 24, 2016. 